\title{
Large Platelets to Total Platelets Ratio Measurement
}

National Cancer Institute

\section{Source}

National Cancer Institute. Large Platelets to Total Platelets Ratio Measurement. NCI

Thesaurus. Code C161353.

The determination of the ratio of large platelets compared to total platelets present in a sample. The measurement may be expressed as a ratio or percentage. 